\title{
Use of the alpha-glucosidase inhibitor acarbose in patients with 'Middleton syndrome': Normal gastric anatomy but with accelerated gastric emptying causing postprandial reactive hypoglycemia and diarrhea
}

\author{
Raymond J Playford FRCP1, Charlotte Pither MRCP², Rui Gao MRCP2, Stephen J Middleton FRCP2
}

\begin{abstract}
RJ Playford, C Pither, R Gao, SJ Middleton. Use of the alphaglucosidase inhibitor acarbose in patients with 'Middleton syndrome': Normal gastric anatomy but with accelerated gastric emptying causing postprandial reactive hypoglycemia and diarrhea. Can J Gastroenterol 2013;27(7):403-404.

Postprandial reactive hypoglycemia, early satiety and diarrhea are well-recognized side effects following full or partial gastrectomy or gastric bypass. It has only recently been realized, however, that patients with normal gastric anatomy may experience similar symptoms and signs due to primary accelerated gastric emptying (Middleton syndrome). In previous case studies, patients responded well to the use of dietary modification (frequent small-volume meals) alone. The authors describe two patients with this syndrome who continued to experience symptoms of reactive postprandial hypoglycemia despite dietary intervention but became asymptomatic following the addition of the alpha-glucosidase inhibitor acarbose.
\end{abstract}

Key Words: Diarrhea; Dumping syndrome; Gastric emptying; Gastric motility; Hypoglycemia
L'utilisation de l'acarbose, un inhibiteur de l'alphaglucosidase chez les patients ayant le syndrome de Middleton : Une anatomie gastrique normale, mais une vidange gastrique accélérée qui provoque une hypoglycémie réactive postpriandale et une diarrhée

\begin{abstract}
L'hypoglycémie réactive postprandiale, la satiété précoce et la diarrhée sont des effets secondaires bien connus de la gastrectomie partielle et du pontage gastrique. Toutefois, on s'est rendu compte récemment que les patients ayant une anatomie gastrique normale peuvent présenter des signes et symptômes similaires en raison d'une vidange gastrique accélérée (syndrome de Middleton). Dans les études de cas précédentes, les patients répondaient bien à une simple modification du régime (des repas fréquents à petit volume). Les auteurs décrivent le cas de deux patients atteints de ce syndrome qui ont continué de présenter des symptômes d'hypoglycémie réactive postprandiale malgré une intervention diététique, mais qui sont devenus asymptomatiques après l'ajout d'acarbose, un inhibiteur de l'alpha-glucosidase.
\end{abstract}

astric bypass or resection for morbid obesity or malignancy are $\mathbf{J}_{\text {well-recognized causes of early satiety, diarrhea and postprandial }}$ reactive hypoglycemia due to the rapid entry of nutrients into the small intestine. In contrast, the association of identical signs and symptoms, including reactive hypoglycemia with normal gastric anatomy but accelerated gastric emptying, has only recently been recognized. Middleton et al (1) initially reported this association as a case report; subsequently, a more detailed description of the syndrome was provided in a series of six patients (2). In both of these publications, most patient's symptoms were adequately controlled through dietary modification (introduction of small frequent meals). The present article describes two patients with this syndrome who remained symptomatic following dietary modification but responded well to the introduction of the alpha-glucosidase inhibitor acarbose.

\section{Case 1}

A 53-year-old Caucasian woman presented with a two-year history of diarrhea. She had experienced constipation since childhood. Associated symptoms included abdominal distension approximately $30 \mathrm{~min}$ after eating, which was often accompanied by diarrhea. She reported severe fatigue, cognitive impairment, weakness, tremor and dizziness approximately $2 \mathrm{~h}$ to $3 \mathrm{~h}$ after eating. During such an episode, she also experienced syncope that was followed by transient memory loss. She reported no allergies, was a nonsmoker and consumed approximately 20 units of alcohol per week. Her only medication was fluoxetine for depression. Physical examination was unremarkable and there was no evidence of an autonomic neuropathy. Routine

\begin{abstract}
laboratory tests, including tissue transglutaminase, short synacthen test, thyroid function, urinary 5-hydroxy-indole-acetic acid and vanillylmandelic acid were normal. Similarly, no abnormalities were found on additional investigations including colonoscopy, 23-Seleno-25homo-tauro-cholate (SeHCAT) retention study and glucose hydrogen breath test. Scintigraphic whole gut transit time using indium diethylenetriaminepentaacetic acid in water (3), revealed rapid gastric emptying with only $9 \%$ of liquid remaining in the stomach at $26 \mathrm{~min}$. An extended oral glucose tolerance test with a standard $75 \mathrm{~g}$ glucose load (4) demonstrated an appropriate rise in glucose level and return to baseline at $60 \mathrm{~min}$ but a subsequent fall to $2.8 \mathrm{mmol} / \mathrm{L}$ at $120 \mathrm{~min}$ at which time her hypoglycemic symptoms occurred (Figure 1). A diagnosis of idiopathic accelerated gastric emptying and reactive hypoglycemia was made. She was treated with a 'grazing diet' (eating regular small meals), which settled her diarrhea symptoms but the hypoglycemic symptoms did not resolve. She was given acarbose $50 \mathrm{mg}$ twice per day before her two main meals, with near complete resolution of symptoms.
\end{abstract}

\section{Case 2}

A 26-year-old woman presented with abdominal discomfort and diarrhea in the postprandial period followed by severe debilitating tiredness when she would often fall asleep. This was frequently associated with nausea and malaise. She took no alcohol, was a nonsmoker and was receiving thyroxine replacement therapy. Physical examination was unremarkable and there were no signs of autonomic neuropathy. Routine laboratory blood tests, thyroid function, duodenal and colonic

\footnotetext{
${ }^{1}$ Office of the Vice Chancellor, Plymouth University, Plymouth; ${ }^{2}$ Department of Gastroenterology Addenbrooke's, Cambridge University Teaching Hospital

NHS Trust, Hills Road, Cambridge, United Kingdom

Correspondence and reprints: Prof Raymond J Playford, Plymouth University, Drake Circus, Plymouth, Devon, PL4 8AA, United Kingdom.

Telephone 44-0-175-258-2000, fax 44-0-175-258-2011, e-mail raymond.playford@plymouth.ac.uk

Received for publication May 8, 2013. Accepted May 12, 2013
} 


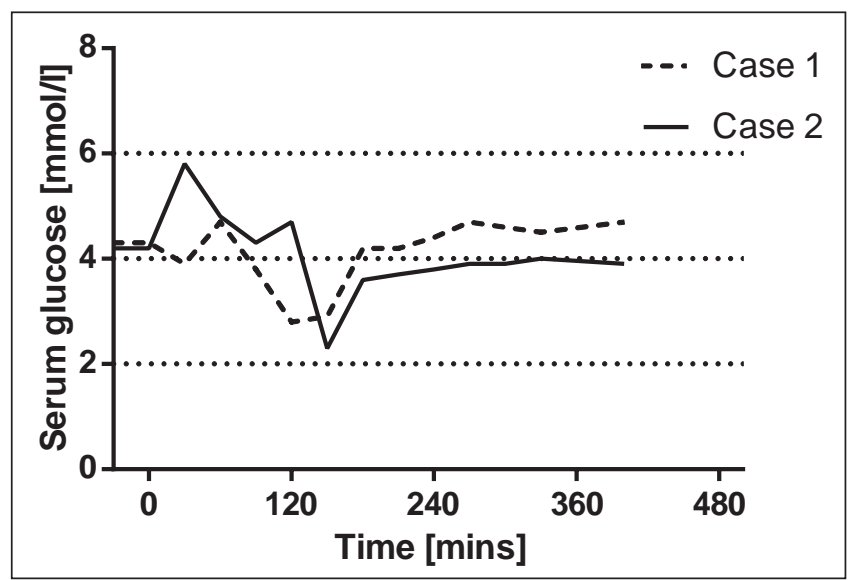

Figure 1) Results of an extended glucose tolerance test, using a standard $75 \mathrm{~g}$ glucose load. In both patients, an appropriate rise in serum glucose and return to baseline in $30 \mathrm{~min}$ was apparent. However, both exhibited a subsequent fall corresponding to the onset of symptoms

biopsies, a short synacthen test and a SeHCAT retention study were normal. Fasting gut hormone levels, glucose hydrogen breath test, video capsule endoscopy, abdominal computed tomography scan and fecal elastase were also normal. A scintigraphic solid-phase gastric emptying (5) study revealed accelerated gastric emptying with a half emptying time of $26 \mathrm{~min}$. An extended glucose tolerance test with a standard $75 \mathrm{~g}$ glucose load demonstrated an appropriate rise in serum glucose and return to baseline in $30 \mathrm{~min}$ but a subsequent fall to $2.3 \mathrm{mmol} / \mathrm{L}$ at

\section{REFERENCES}

1. Middleton SJ, Balan K. Post-prandial reactive hypoglycaemia and diarrhea caused by idiopathic accelerated gastric emptying: A case report. J Med Case Rep 2011;5:177.

2. Middleton SJ, Balan K. Idiopathic accelerated gastric emptying presenting in adults with post-prandial diarrhea and reactive hypoglycemia: A case series. J Med Case Rep 2012;6:132.

3. Sørensen M, Johansen OE. Idiopathic reactive hypoglycaemia prevalence and effect of fibre on glucose excursions. Scand J Clin Lab Invest 2010;70:385-91.

4. Bonapace ES, Maurer AH, Davidoff S, Krevsky B, Fisher RS, Parkman HP. Whole gut transit scintigraphy in the clinical
150 min, at which time her hypoglycemic symptoms occurred (Figure 1). A diagnosis of primary accelerated gastric emptying was made and she was advised to adhere to a 'grazing diet'. This dietary approach settled her symptoms of diarrhea but did not resolve the hypoglycemic symptoms. She was, therefore, given acarbose $50 \mathrm{mg}$ before her main meals two or three times per day, which resulted in a near complete resolution of symptoms, with only mild fatigue occurring after a large meal.

\section{DISCUSSION}

Motility disorders of the gastrointestinal tract are not easily identified by their associated symptoms (6), which can consequently lead to delays in diagnosis. A study involving 649 consecutive patients who underwent scintgraphic gastric emptying studies (7) reported that in patients with suspected accelerated gastric emptying on clinical grounds, this was confirmed in $69 \%$, but $7 \%$ demonstrated delayed gastric emptying. Of patients suspected to have gastroparesis, only $29 \%$ were found to demonstrate delayed gastric emptying on scintigraphic testing and $23 \%$ had accelerated gastric emptying. This study implies that the clinical diagnosis of gastric dysmotility is difficult because symptoms do not reliably reflect the underlying nature of the motility disorder, and symptoms believed to indicate gastroparesis may be caused by accelerated gastric emptying.

Early satiety, postprandial diarrhea and subsequent hypoglycemic symptoms, such as nausea, fatigue, sweating and cognitive impairment, should lead the clinician to consider the diagnosis of 'Middleton syndrome', in which the primary abnormality is accelerated gastric emptying. Symptoms usually respond well to dietary intervention but, as described in the present report, may occasionally require additional treatment with an alpha-glucosidase inhibitor, such as acarbose, to resolve refractory hypoglycemic symptoms.

evaluation of patients with upper and lower gastrointestinal symptoms. Am J Gastroenterol 2000;95:2838-47.

5. Malmud LS, Fisher RS, Knight LC, Rock E. Scintigraphic evaluation of gastric emptying. Seminar Nuclear Med 1982;12:116-25.

6. Balan K, Alwis L, Sonoda LI, Pawaroo D, Parry-Jones DR, Middleton S. Utility of whole gut transit scintigraphy in patients with chronic gastrointestinal symptoms. Nucl Med Commun 2010;31:328-33.

7. Balan K, Sonoda LI, Seshadri N, Solanki C, Middleton S. Clinical significance of scintigraphic rapid gastric emptying. Nucl Med Commun 2011;32:1185-9. 


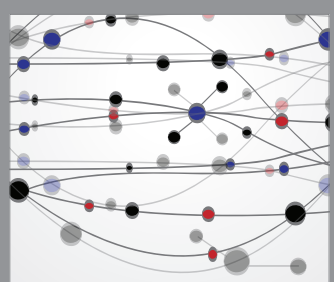

The Scientific World Journal
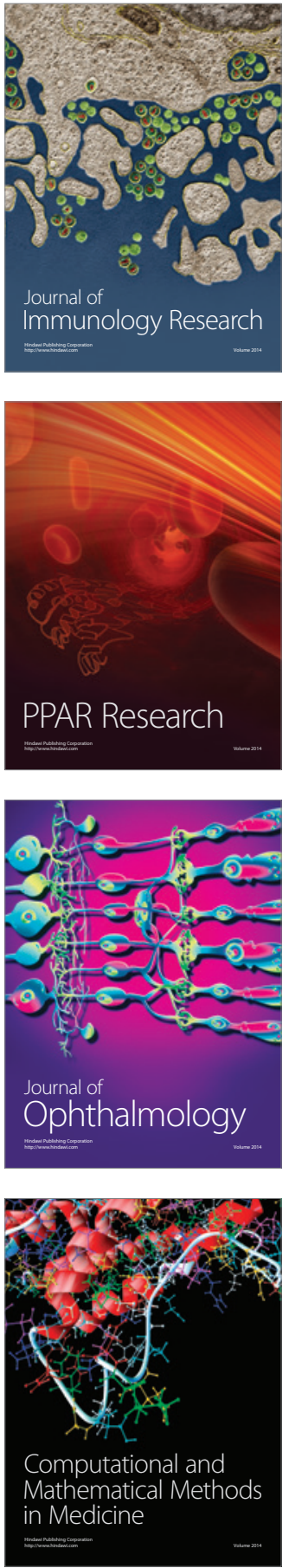

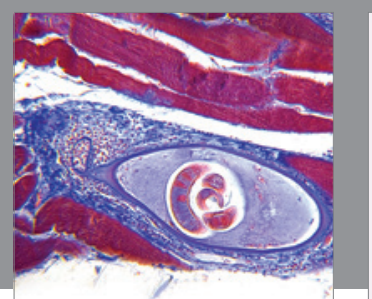

Gastroenterology Research and Practice

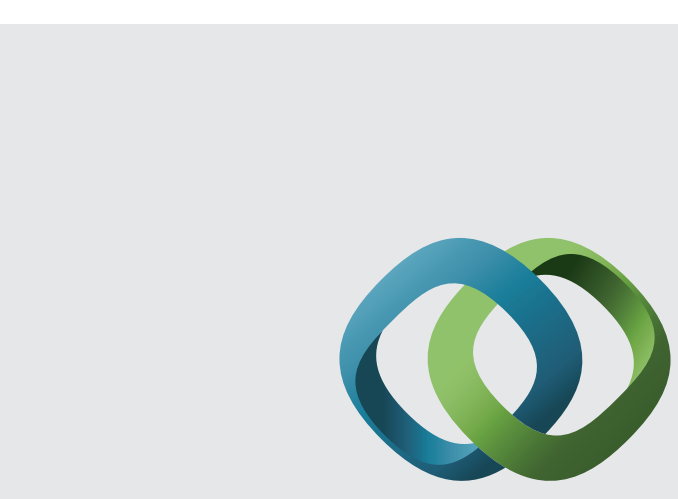

\section{Hindawi}

Submit your manuscripts at

http://www.hindawi.com
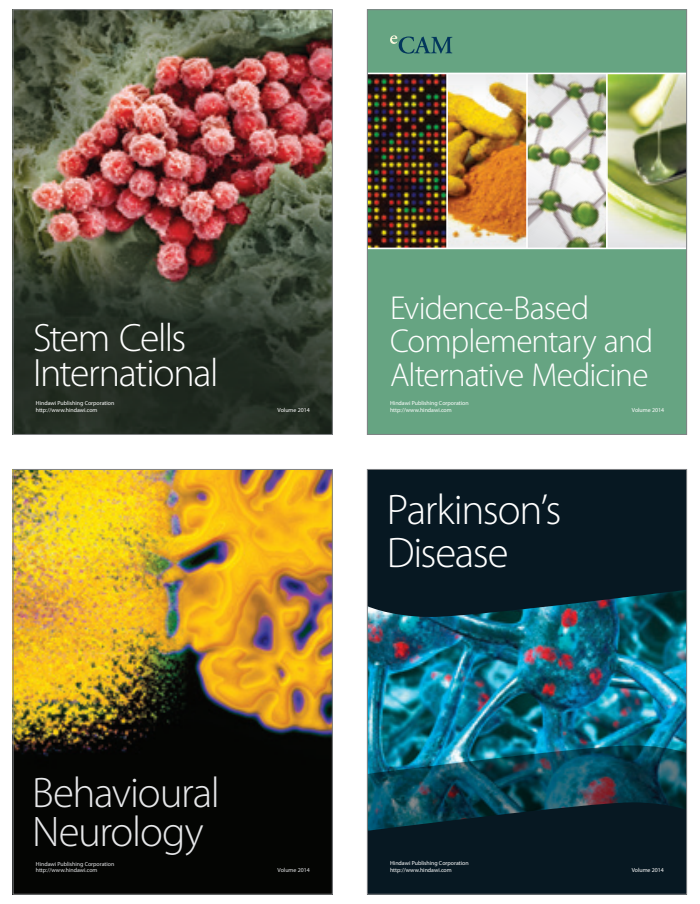
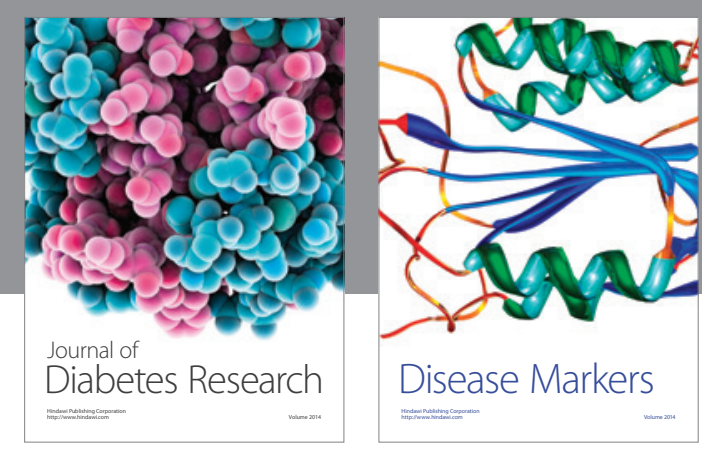

Disease Markers
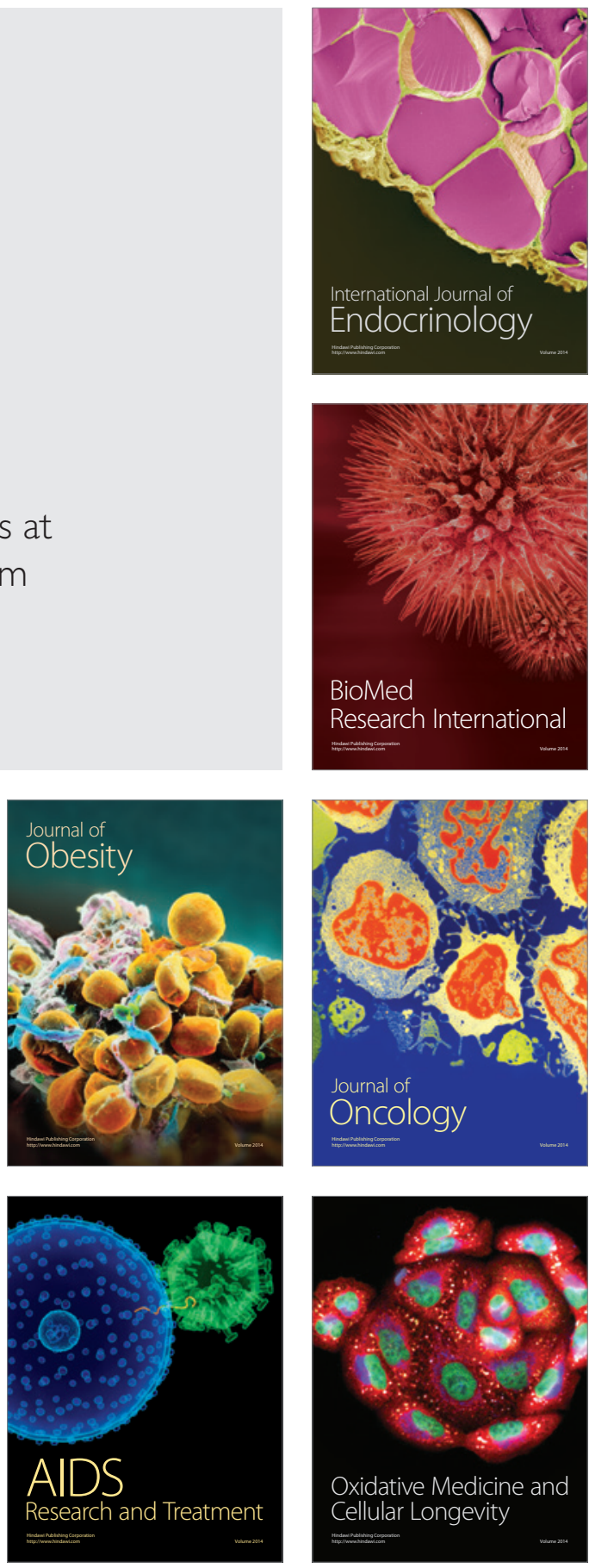